\title{
Por uma historiografia literária sentimental: formação e modernidade em Antonio Candido
}

\author{
For a sentimental literary historiography: Formation and modernity in \\ Antonio Candido
}

\author{
Henrique Pinheiro Costa Gaio \\ henriquecgaio@gmail.com \\ Pós-doutorado \\ Universidade Federal de Ouro Preto \\ Rua do Seminário, s/n, Centro \\ 35420-000 - Mariana - Minas Gerais \\ Brasil
}

\begin{abstract}
Resumo
Este artigo pretende realizar uma análise da historiografia literária de Antonio Candido, expressa em Formação da literatura brasileira (1959). Compreender a arquitetura textual de Candido como uma narrativa de passagem, na qual são selecionados os momentos decisivos da literatura brasileira, indica uma permanente tensão entre tradição e modernidade e o caráter incompleto de nossa formação literária. Assim, de maneira a abarcar a relação entre tradição e modernidade, fundadora de uma literatura nacional, propomos uma chave de leitura schilleriana. Desse modo, talvez seja possível, a partir da passagem de uma literatura de traço ingênuo para uma de caráter sentimental, identificar o sentido da teoria da formação da literatura brasileira expressa por Candido.
\end{abstract}

\section{Palavras-chave}

Modernidade; Formação; Antonio Candido.

\begin{abstract}
This article analyzes the literary historiography of Antonio Candido, expressed in the book Formação da literatura brasileira (1959). Understanding Candido's textual architecture as a narrative of transition, in which the crucial moments of Brazilian literature are selected, suggests a permanent tension between tradition and modernity, and the unfinished character of our literary formation. Thus, aiming to grasp the relation between tradition and modernity, as the ground of a national literature, we propose a schillerian approach. Perhaps through the passage from a naïve literature to a sentimental one, it may be possible to identify the sense of Brazilian literature formation's theory expressed by Candido.
\end{abstract}

Keywords

Modernity; Formation; Antonio Candido.

Recebido em: 8/9/2016

Aprovado em: 15/8/2017 
Formação da literatura brasileira, de Antonio Candido, publicado em 1959, possui um desenho narrativo peculiar. Ao contrário da completude, amiúde almejada nos modelos tradicionais de historiografia literária, em que a origem configura o incontornável início e a narrativa estende-se ao presente da escrita, Candido seleciona o que considera os momentos decisivos na formação da maturidade literária nacional. Sua escrita, desse modo, busca captar o movimento transitório: a passagem da normatividade neoclássica, ajuizadora de gostos e legisladora da produção poética, para a emergência de uma literatura romântica responsável por um novo tipo de sensibilidade e por conceder um traço local às letras. Nesse sentido, o momento inicial para a compreensão da conquista da maturidade intelectual, segundo a perspectiva histórico-cultural adotada pelo autor, seria a formação de uma rotina literária baseada em preceptivas neoclássicas. A aclimatação de temas universais e a sedimentação das formas desempenham papel constitutivo fulcral, pois condicionam o posterior surgimento de um sentimento de cores nativas. A síntese encaminhada na arquitetura textual, portanto, prevê uma espécie de fusão entre a imaginação europeia e a sensibilidade nacional.

Antonio Candido justifica a baliza temporal adotada como decisiva, 17501880, fazendo distinção entre literatura e manifestações literárias. O que definiria a literatura como sistema simbólico seria a existência de um comércio regular entre autor e leitor, calcado na transmissão de uma tradição através das obras. O aspecto orgânico da literatura se anuncia na "existência de um conjunto de produtores literários, mais ou menos conscientes de seu papel; um conjunto de receptores, formando os diferentes tipos de público, sem os quais a obra não vive; um mecanismo transmissor, [...], que liga uns aos outros" (CANDIDO 2009, p. 25). Autor, obra e leitor formariam a tríade necessária para a existência do que o crítico define como literatura; nesses termos, o que estaria em questão seria a regularidade das trocas simbólicas e a formação de uma tradição no jogo tenso entre o universal e o local. Por outro lado, as obras sem lastro em termos de influência, ou que não se originassem dessa tensão, funcionariam apenas como espasmos literários, manifestações avulsas que deveriam ser excluídas de uma narrativa que visasse a delinear a formação da literatura brasileira. O sistema almeja, através do jogo de influências que marcam a trajetória intelectual nacional, identificar sobretudo "uma continuidade ininterrupta de obras e autores, cientes quase sempre de integrarem um processo de formação literária". A tradição, dessa maneira, revela-se como imperioso e consciente ato de transmissão ou, como na imagem sugerida por Candido, uma "espécie de transmissão de tocha entre corredores". Somente verificada tal continuidade ou permanências seria possível tecer o fio que permite historicizar a forma literária, pois "sem esta tradição não há literatura, como fenômeno de civilização" (CANDIDO 2009, p. 26).

Literatura, portanto, assenta-se não somente nas trocas simbólicas, mas, sobretudo, na interferência que o passado exerce sobre o presente por meio da influência. A consciência exigida pelo sistema literário proposto aponta para a dimensão empenhada da criação literária, como também no reconhecimento 
do passado como fonte que não deve ser desprezada na apreciação crítica da literatura, possibilitando identificar constâncias e inovações. Vale mencionar que a tradição não adquire aqui uma rigidez cadavérica ou o aspecto de fardo nietzschiano, mas configura-se em um código literário acessível ao autor e ao público e que permite aquilatar as novas obras e proporcionar uma meta de superação. A noção de sistema literário, ao prever movimento que se inicia com a criação poética, mas somente se conclui com a recepção, enfatiza não o passado em si, mas uma sempiterna reconfiguração do passado pelo presente. Desse modo, a tradição teria a função de demarcar certos padrões que permitissem a feitura de quadro comparativo amplo, possibilitando também a "transmissão de algo entre os homens, e o conjunto de elementos transmitidos, formando padrões que se impõem ao pensamento ou ao comportamento, e aos quais somos obrigados a nos referir, para aceitar ou rejeitar" (CANDIDO 2009, p. 25-26).

O que está em jogo num primeiro instante seria a identificação do momento de formação da tradição, quando se supera a simples manifestação literária e a produção pretérita adquire status de literatura. Mais do que uma reminiscência do passado, a tradição deveria manifestar-se em sucessivos presentes, em ininterrupto diálogo entre passado e presente, sempre pendulando entre aceitação e negação, entre conformismo e sedição. Em suma, a tradição, tal como preconizada por Candido, manifesta-se enquanto processo formativo, no qual a relevância do passado literário, que se materializa num jogo de referências cruzadas no interior das obras, não reside em si mesma, mas na relação possível com o todo, com certo legado letrado e devir literário.

Com base na concepção de sistema literário e no aspecto formativo que configura o sentido da historiografia literária de Antonio Candido, a questão que pretendemos destacar é que, para além dos avanços poéticos da ficcionalidade, a narrativa de Formação da literatura brasileira orienta-se para a descrição do aparecimento gradual de uma dimensão autorreferente da literatura nacional. Sendo assim, a noção de sistema literário indica a valorização do jogo intertextual estabelecido entre os autores, as referências compartilhadas, a capacidade de uso criativo de um repertório comum e, sobretudo, a reflexão de cunho crítico que torna a tradição um legado profícuo e referência inexorável para aquilatar a produção literária nacional. A formação da literatura brasileira, nessa perspectiva, parece ser descrita como um progressivo processo de perda da ingenuidade, calcada numa inspiração de natureza intuitiva, e o cultivo de uma sensibilidade intermediada pela capacidade de reflexão crítica. Tal estratégia de síntese formativa da historiografia literária permite uma aproximação ensaística com a reflexão schilleriana sobre o poeta ingênuo e o sentimental.

\section{Costurando temporalidades}

Ao se colocar deliberadamente no ângulo dos nossos primeiros românticos, Candido, mesmo reconhecendo os equívocos advindos de tal visão, busca narrar uma história dos brasileiros no seu desejo de ter uma literatura. Sua narrativa prioriza, assim, a descrição da vontade e do empenho no desenvolvimento de uma consciência literária nacional, uma atitude reflexiva que permita a avaliação 
do legado luso-brasileiro e, posteriormente, a construção de uma tradição nacional. Não por acaso, seu panorama formativo se encerra com o Instinto de nacionalidade (1873), de Machado de Assis. Talvez ainda mais significativa seja a omissão deliberada da produção ficcional de Machado, inclusive a publicação de Memórias póstumas de Brás Cubas (1880), considerada obra basilar para a maturidade do escritor, destacando a centralidade da crítica no pretendido panorama literário brasileiro.

A opção pelo crítico em detrimento do ficcionista merece considerações. No prefácio da $1^{a}$ edição, Candido explica que a exclusão do Machado de Assis romântico o obrigaria a fragmentar uma obra cuja unidade vinha sendo reforçada pela fortuna crítica machadiana. ${ }^{1}$ Depreende-se de tal consideração que somente a primeira fase da produção machadiana se adequaria ao sistema erigido em Formação: a fase realista que se segue à publicação de Memórias póstumas extrapolaria a proposta de uma narrativa de passagem, pois exemplificaria uma solução estética que, em certa medida, o colocasse para além dos impasses provocados pela tensão entre o local e o universal ou entre tradição e modernidade. Em Instinto de nacionalidade, por sua vez, Machado destaca o lento trabalho de formação literária que foi iniciado com os árcades e estende-se ao momento romântico. Vejamos o trecho machadiano que serve como desfecho para a historiografia literária de Antonio Candido:

Não há dúvida que uma literatura, sobretudo uma literatura nascente, deve principalmente alimentar-se dos assuntos que lhe oferece a sua região; mas não estabeleçamos doutrinas tão absolutas que a empobreçam. O que se deve exigir do escritor, antes de tudo, é certo sentimento íntimo que o torne homem de seu tempo e do seu país, ainda quando trate de assuntos remotos no tempo e no espaço. Esta é a outra independência que não tem sete de setembro nem campo do Ipiranga; não se fará num dia, mas pausadamente, para sair mais duradoura; não será obra de uma geração nem duas; muitas trabalharão para ela até perfazê-la de todo (MACHADO DE ASSIS 1974, p. 343-351).

A mobilização da perspectiva crítica de Machado de Assis como epílogo do arco narrativo funciona como síntese que torna transparente a similitude entre o panorama crítico dos autores, pois em ambos a noção de formação mostra-se como ponto estruturante da peculiar relação entre passado, presente e futuro. A sincronia dos balanços literários funciona como uma espécie de efeito de eco, como artifício que, ao mesmo tempo em que demarca a fundação de uma tradição crítica, permite indicar que a teoria da formação desloca-se de uma nacionalidade constituída em uma origem remota ou recente para um devir em aberto (Cf. BAPTISTA 2005, p. 64). No entanto, o sentido teleológico, que pode ser reconhecido em ambos, não minimiza o empenho em dialogar com os antecessores locais, numa indicação de avanços e recuos, engendrando

\footnotetext{
${ }^{1}$ Tal explicação, é relevante apontar, não deixa de ser também o reconhecimento de que a ausência da ficção de Machado representava uma lacuna no seu quadro formativo: "Outra falha me parece, agora, a exclusão do Machado de Assis romântico no estudo da ficção, que não quis empreender, como se verá, para não seccionar uma obra cuja unidade é cada vez mais patente aos estudiosos. Caso o livro alcance segunda edição pensarei em sanar estas e outras lacunas" (CANDIDO 2009, p. 14).
} 
conscientemente a tessitura de uma tradição como condição de possibilidade para a formação. A sensibilidade crítica machadiana reverbera a proposta formativa de Candido, provocando uma espécie de superposição de tempos distintos, costurando temporalidades no esforço de engendrar sínteses provenientes da tensão entre o ideal de modernização, feito prognóstico de futuro, e a realidade histórica que indica a permanência do passado. ${ }^{2}$

Em outras palavras, a concepção de que a maturidade depende de uma atitude reflexiva diante do passado e do presente da produção literária, num movimento de depuração do gosto e de educação estética, mostra-se visível nas palavras de Machado de Assis e na perspectiva formativa de Candido. Segundo Leopoldo Waizbort, "se para Machado de Assis falta a crítica, como dimensão autorreflexiva da literatura nacional, para Antonio Candido o diagnóstico machadiano da falta já é, ele mesmo, a dimensão autorreflexiva" (WAIZBORT 2007, p. 141). Nesse sentido, a utilização da crítica machadiana serve como desfecho exemplar talvez não só pelo alerta contido, mas também pelo movimento marcado pela substituição de um diagnóstico do instinto de nacionalidade por um sentimento íntimo, demonstrando a perda de uma ingenuidade e o aparecimento de uma dimensão sentimental-reflexiva. A ingenuidade no trato com a natureza vai gradativamente cedendo lugar ao artifício do escritor. Dessa maneira, em consonância com o movimento proposto por Candido, a reflexão schilleriana indica que o ingênuo e o sentimental se diferenciam "pelo fato de o primeiro referir-se a uma maneira natural ou instintiva de criar, ao passo que o segundo se destaca por um procedimento eminentemente reflexivo" (SUZUKI 1991, p. 31).

No momento decisivo de constatar a emergência da literatura nacional, Antonio Candido expõe em primeiro plano não o modelo europeu, mas a sensibilidade local intermediada e depurada pelo discernimento crítico. Dessa forma, pode-se identificar uma importante inflexão poética: o aparecimento de um sentimentalismo mais brando, menos lacrimoso e atenuado pelo artifício da escrita. Se os folhetins moralistas e edificantes, repletos de peripécias, possuíam público cativo, marcando a submissão do autor ao gosto médio do público, a expansão do lirismo - exemplificada em Fagundes Varela e Castro Alves deixava entrever um novo arranjo estético, uma literatura menos epidérmica por fazer uso de uma tradição que começava a ganhar solidez. Não se tratada formação de um cânone de mestres da ficção: esse passo extrapola as páginas de Formação da literatura brasileira. Importa antes o discernimento, a crítica, a criação consciente do artefato literário do que o reconhecimento de uma obra de gênio que pudesse balizar uma espécie de genealogia da literatura nacional.

Assim, o momento de formação diz respeito, sobretudo, à gradativa capacidade reflexiva dos literatos, à emergência de uma literatura sentimental. Sublinhar pequenos experimentos estéticos, variações de timbre, retirar o melhor efeito de um velho recurso delineiam nossa tradição e apontam para o esforço que envolve gerações. A consciência crítica, que ganha maior solidez 
em fins do século XIX por conta de um deliberado esforço de edificação de uma tradição, atesta a maturidade literária nacional não pela publicação de Memórias póstumas de Brás Cubas, pela genialidade do ficcionista que se mantém como exceção, mas pela obra contínua e de menor vulto que estabelece o hábito de olhar e dialogar com os antecessores. ${ }^{3}$ Sobre o surgimento dessa nova sensibilidade, diz-nos Candido:

São traços importantes para completar a expressão da nova sensibilidade, amaciando, colorindo, adoçando o verso português a fim de dobrá-lo às suas exigências, num processo de contrapeso ao estilo regular e lógico do Classicismo. Junto ao legado harmônico da Arcádia e às suas nobres cadências prepara-se deste modo uma invasão de melodia que habituará o ouvido à melopeia, facilitando, desintelectualizando a percepção lírica. A sensibilidade natural começa a se tornar sentimental e procura as formas expressionais adequadas, que o Romantismo levará às últimas consequências (CANDIDO 2009, p. 113).

Trata-se, portanto, de sublinhar uma nova sensibilidade, que funciona não como contraponto à regularidade classicista, como momento de ruptura e negação, mas como algo que é engendrado dialeticamente por meio de uma contínua formação. E modelar tal nova sensibilidade, por meio do jogo tenso entre tradição e modernidade, requer uma nova forma de expressão provocada pelo desejo de avanços estéticos e pela busca por autonomia literária: segundo Candido, "só quando aparecerem poetas capazes de superar a estreita preocupação ilustrada e comunicar no verso a beleza do mundo e a emoção dos seres, é que esta geração alcançará verdadeiramente a poesia" (CANDIDO 2009, p. 117). A nova sensibilidade tornou as preceptivas clássicas por demais estreitas, impôs uma limitação às convenções e assinalou uma nova exigência de forma.

\section{A emergência de uma sensibilidade fundadora}

Valendo-nos ainda da reflexão schilleriana, que opõe a criação ingênua à sentimental, talvez seja profícuo testar, a partir da armação narrativa de Candido, a possibilidade da seguinte chave de leitura: o par antitético clássico-romântico como extensão do ingênuo-sentimental. Vejamos as palavras de Goethe que explicam a sinonímia schilleriana clássico-ingênuo e romântico-sentimental:

O conceito de poesia clássica e romântica, que agora corre o mundo todo e causa tanto conflito e divergência... provém originalmente de mim e de Schiller. Na poesia, tinha eu por máxima o procedimento objetivo e pretendia que apenas este valesse. Schiller, porém, que atuava

\footnotetext{
${ }^{3}$ Ao descrever uma poética da emulação em Machado de Assis, João Cezar de Castro Rocha chamou a atenção para esse uso dinâmico e inventivo da tradição como marca da produção do autor. Ao destacar a transição do jovem moralista para o maduro e irônico autor de Memórias póstumas de Brás Cubas, sublinha sua capacidade de leitura crítica como promotora de uma reinvenção de sua poética, ruminar a tradição e dar-lhe uma feição original através de uma recombinação de elementos. Tal perspectiva, ignorando as nuances do argumento e seu viés deliberadamente anacrônico, corrobora o argumento aqui defendido que aponta para a capacidade de reflexão como ato fundador da modernidade literária. Segundo o autor, "o estabelecimento de tal equivalência entre ruminação e aemulatio exige um passo suplementar. Afinal, se a ruminação pressupõe um ato interpretativo, a técnica da aemulatio necessariamente vai além, propondo um ato inventivo através da incorporação do alheio. Hermenêutica com dentição afiada, o resgate anacrônico da aemulatio possui sabor antropofágico" (ROCHA 2013, p. 159).
} 
de forma inteiramente subjetiva, considerava a sua maneira a correta e, para defender-se de mim, escreveu o ensaio sobre poesia ingênua e sentimental. Demonstrou-me que eu próprio, contra a vontade, sou romântico e que, pelo predomínio da sensibilidade, minha Ifigênia não é assim tão clássica e tão no sentido antigo como talvez se pudesse crer. Os Schlegel aproveitaram a ideia, de modo que agora ela se difundiu pelo mundo inteiro, e todos falam de classicismo e romantismo, nos quais há cinquenta anos ninguém pensava (GOETHE apud SUZUKI 1991, p. 23).

Não se trata de recorrer a nominalismos ociosos, mas sim de se estabelecer uma aproximação ensaística que possa potencializar a interpretação proposta: pela distinção entre o ingênuo e o sentimental, ou mesmo entre clássico e romântico, a tensão entre natureza e artifício ganha o primeiro plano. Enquanto os ingênuos buscavam a naturalidade da expressão, uma simplicidade que se adequava ao padrão do belo, os sentimentais procuravam reencontrar a natureza por meio do artifício poético. O sentimentalismo, na perspectiva schilleriana da modernidade, representa a atitude reflexiva na busca pela naturalidade perdida, que nunca será satisfeita, tornando-se, no limite, uma espécie de segunda natureza. O procedimento criativo moderno, desse modo, seria entremeado pela cultura, por um projeto de educação estética que visa a alcançar uma dimensão universal da experiência - seguindo o sistema kantiano, tal dimensão seria somente atingida através de uma relação harmoniosa entre a faculdade do entendimento e da imaginação.

A passagem do superficial nacionalismo descritivo romântico, no qual a natureza ganha tom idílico, para um sentimento íntimo, através do qual uma interioridade nacional adquire forma, revela certa atenuação da perspectiva nacionalista expressa em Formação. O nacionalismo que se mostrou como pilar das historiografias literárias do século XIX, tocado quase sempre por uma dimensão política, ganha outra configuração, donde se depreende uma tentativa de superação da dicotomia entre a experiência e a imaginação. A sensibilidade alimentada por uma ambiência nacional e a imaginação motivada pela forma europeia parecem dar origem a uma nova possibilidade de síntese. Uma síntese que não vislumbra apaziguar os contrários, mas sim conceder uma resposta criativa e depurada de tal tensão, capaz de imputar um sentido moderno à formação literária nacional. Candido parece indicar uma espécie de solução dialética para superar a moléstia de Nabuco, a qual grassava na intelectualidade brasileira, fazendo com que a subjetividade se forjasse quase que inevitavelmente em conformação com uma imaginação europeia e com que o sentimento nacional se restringisse ao lamento da distância física da pátria. ${ }^{4}$

Segundo a interpretação de Guilherme Simões Gomes Júnior, o arcadismo por um triz não seria excluído do panorama literário desenhado por Antonio

\footnotetext{
4 Joaquim Nabuco, em Minha Formação (1900), aponta para o vazio estético e histórico do Novo Mundo, para a verdadeira solidão de espírito que apaga as reminiscências do passado e condena os brasileiros à instabilidade: "A instabilidade a que me refiro provém de que na América falta à paisagem, à vida, ao horizonte, à arquitetura, a tudo o que nos cerca, o fundo histórico, a perspectiva humana; e que na Europa nos falta a pátria, isto é, a fôrma em que cada um de nós foi vazado ao nascer. De um lado do mar sente-se a ausência do mundo; do outro, a ausência do país. O sentimento em nós é brasileiro, a imaginação europeia" (NABUCO 1999, p. 49). Sobre a formação da subjetividade em Joaquim Nabuco, ver Araujo (2004; 2001).
} 
Candido, pois constituía um momento de transição entre o contorcionismo retórico, expressão da decadência barroca e de um gosto duvidoso, e a solução esteticamente equilibrada, verificada em Cláudio Manuel da Costa e que precede a autoconsciência nacional do romantismo (GOMES JÚNIOR 1998, p. 140-41). Todavia, a força argumentativa de Candido deve-se justamente a essa passagem, pois tal leitura crepuscular garantiria a dosagem de elementos externos, que constituiriam uma tradição mais ampla e elementos internos que emergem da própria plasticidade dos temas locais: Cláudio Manuel da Costa estaria no limiar entre o bairrismo mineiro e os padrões eruditos da Europa, uma espécie de caipira que "procura disfarçar as marcas de origem acentuando os traços aprendidos na cidade" (CANDIDO 2009, p. 88). Tal tentativa de escamotear um traço espontâneo por meio das convenções funciona como uma espécie de metonímia de nossa formação. Essa permanente tensão condiciona as principais manifestações literárias do período e expressa uma dualidade que se mantém em suspenso, aguardando uma posterior síntese em que sejam reconfigurados os diferentes elementos verificados na poética do autor, o que, por sua vez, permitiria transformar "inconscientemente o cenário natural em estado da sensibilidade" (CANDIDO 2009, p. 89). ${ }^{5}$

A transitoriedade mostra-se estrutural para a formação literária brasileira, seguindo o argumento de Candido, pois o afã por totalidade não impõe a completude, interessa-se antes pela dialética formativa - por isso, arcadismo e romantismo se equivalem enquanto elementos fundadores. A opção pelo arcadismo como uma espécie de antessala de nossa literatura nacional reside na força formadora do classicismo, uma espécie de educação estética que marca a presença do Ocidente, que, ao consolidar-se, mesmo que como emulação, permite a emergência da temática nacional. Incorporados esses elementos eruditos em terras incultas, poderíamos esgarçar a tradição através do uso consciente e afetivo de uma expressão de traços locais.

Presença indelével em momentos de transição, o maneirismo expressão literária sem músculo, mero exercício formal envelhecido pelo uso indiscriminado - aproxima-se da noção de rotina, termos que se confundem na própria narrativa de Formação. Quando os modelos tornam-se moeda corrente, configuram uma rotina e cria-se uma tradição assentada num diálogo literário entre antecessores e contemporâneos, ao mesmo tempo em que se impõe o cansaço das convenções. Em ato contínuo, a decrepitude de temas e formas engendra sua própria negação, ou, como diz Candido, "cada período literário é ao mesmo tempo um jardim e um cemitério" (CANDIDO 2009, p. 201). Vejamos sua colocação a respeito dessa transição que evoca tradição e ruptura:

\footnotetext{
${ }^{5}$ Mostra-se interessante notar que a leitura de Candido atenuou o barroquismo de Cláudio Manuel da Costa pela contenção dos excessos, pois o exagero fora tocado pela temperança clássica. O que deve ser destacado nessa interpretação é justamente a capacidade de pôr em equilíbrio essas influências, abrandando sua força expressiva e o ímpeto para o uso contorcido das metáforas por meio da influência do classicismo. Seu trato artesanal, ao burilar a simplicidade poética, coaduna-se com a expressão de uma emoção pura. A inspiração encontra na tradição uma aliada que lapida sua forma poética, e, exatamente, nessa fusão moderada reside sua força, superando o simples amaneiramento de filtro barroco.
} 
No que estamos analisando, a acentuação de características fez com que a naturalidade neoclássica, penosamente obtida, se tornasse prosaísmo; a elegância, afetação; o Classicismo, frio arrolamento de alegorias; a Ilustração, pedantismo didático. Por outro lado, o mesmo processo ressaltou certas tendências menos ostensivas na fase anterior e agora salientadas pela hipertrofia. Assim, a preocupação geral com o humano, acentuando-se, concentrou-se no indivíduo singular; o culto da natureza propiciou o sentimentalismo, levando ao amolecimento da sensibilidade; a paixão pelas coisas civis desdobrou-se no patriotismo; a devoção religiosa, na pesquisa dos mais refinados estados d'alma (CANDIDO 2009, p. 201).

Apesar do prosaísmo, da afetação, de alegorias mecânicas e do pedantismo das referências didáticas, decorrentes de seu uso repetitivo, como obrigação do espírito culto, o neoclassicismo cumpre seu papel na formação: estabilizou uma rotina e construiu uma espécie de repertório que alimentou a criação literária nacional. Em circunstância diversa, o elenco de normas clássicas admite sua porosidade ao, gradativamente, receber influxos renovadores provenientes do sentimentalismo emergente dos primeiros românticos. Nessa transição, o passo decisivo que se esboça é a transparência de sentimentos locais que serão literariamente organizados.

A opção de Antonio Candido pelo arcadismo como pedra angular de nossa formação não se restringe ao âmbito estético. Além de atento à rotina, engendrada pela noção de sistema, sublinha a consciência política lapidada pelos árcades. Destaca o desenvolvimento cívico como corolário do racionalismo do período, o que implicará as primeiras manifestações do nativismo na poesia de fins do século XVIII. Ainda que disperso e frágil, ali se estabelece um esforço de aclimatação nevrálgico para semear uma sensibilidade literária. De acordo com Candido, as parcas luzes que atingiram a produção literária colonial, ainda ramo secundário dos lusitanos, serviram para alentar certo nativismo bucólico que descreve a natureza nacional de maneira intelectiva, numa tensão ainda não resolvida entre erudição e experiência; no entanto, vale dizer que nesse momento a convenção ainda pesa mais que a sensibilidade na pena do poeta: a normatividade engendra uma ordem estética que estimula a integração com o Ocidente através da literatura. $O$ embate entre a intelecção e a sensibilidade aflora no exercício mimético dos poetas:

O Arcadismo é, pois, consciência de integração: de ajustamento a uma ordem natural, social e literária, decorrendo disso a estética da imitação, por meio da qual o espírito reproduz as formas naturais, não apenas como elas aparecem à razão, mas como as conceberam e recriaram os bons autores da Antiguidade e os que, modernamente, seguiram sua trilha (CANDIDO 2009, p. 53).

Segundo Candido, o inacabamento de nossa formação literária deriva da dificuldade provocada pela dependência em relação aos modelos europeus. Como consequência disso, no âmbito do processo criativo teríamos, por sua vez, um prolongamento da relação ingênua com o ambiente. Todavia, não se pode perder de vista que, num primeiro momento, a dificuldade de moldar as 
preceptivas clássicas em ambiente hostil foi aspecto importante da formação literária nacional, mas que, superada essa aclimatação, seria necessária uma reconfiguração da forma, para que uma nova sensibilidade emergisse. Tal passagem, assim, seria engendrada pelo consciente uso do artifício, pelo esgarçamento dos modelos europeus.

\section{Formação como teoria da modernidade}

Para referendar o momento decisivo da transição de uma sensibilidade árcade para uma romântica, podemos utilizar as palavras de Schiller: "o ingênuo é uma infantilidade, ali onde já não é esperada e, por isso, não pode ser atribuída à infância real no sentido mais estrito". O que está em jogo, dessa maneira, não é uma metáfora organicista da formação literária nacional, mas sim certa inadequação da manutenção de uma ingenuidade clássica em ambiente moderno, onde "a natureza tem de estar certa, e a arte, errada" (SCHILLER 1991, p. 47). Em outras palavras, a questão da modernidade literária não se encerra na insistência da querela de antigos e modernos, mas pressupõe, sobretudo, uma reflexão sobre a própria temporalidade. Se é possível extrair da reflexão schilleriana certa utopia balizada por uma educação estética, o traço distintivo da modernidade que nos interessa para o desenvolvimento do argumento é a condição da diferença como experiência passível de ser tematizada. O reconhecimento da temporalidade enquanto condição de possibilidade da crítica implica uma valorização da dimensão histórico-qualitativa e não meramente cronológica da modernidade (LIMA 1993, p. 153-170; OSBORNE 1992).

A modernidade implicaria, inevitavelmente, a compreensão da dimensão reflexiva nos procedimentos de criação poética, seu caráter de artifício. No entender de Schiller, "atribuímos a um homem uma intenção ingênua se em seus juízos não repara nas artificiais e rebuscadas relações das coisas e atémse unicamente à natureza simples" (SCHILLER 1991, p. 47-49). Ora, não é exatamente essa a passagem que Candido procura descrever em sua narrativa de formação? Não seria, por exemplo, a superação gradual de uma ingenuidade indianista, expressa antes nos árcades e que duplicaria o quadro da natureza, uma das marcas fundadoras do artifício nacional?

Amparados por uma tradição que se constituía com vagar, os escritores sentimental-reflexivos puderam expressar uma sensibilidade particular e um realismo que concediam novas camadas à produção estética. Ao se referir ao papel desempenhado por José de Alencar, não somente no avanço promovido na tópica indianista, mas também em relação ao seu senso de realidade e aos seus estudos de psicologia humana - feito um Balzac em miniatura,$-{ }^{6}$ Antonio Candido concentra-se no domínio do artifício e na capacidade reflexiva como filtro para avaliar a contribuição de Alencar para a formação literária nacional:

\footnotetext{
6 "Isto não quer dizer apenas que Alencar foi melhor romancista ao criá-lo, pois a simplificação dos demais corresponde a outro tipo de ficção, mas que foi capaz de fazer literatura de boa qualidade tanto dentro do esquematismo psicológico quanto do senso da realidade humana. Por estender-se da poesia ao realismo cotidiano, e da visão heroica à observação da sociedade, a sua obra tem a amplitude que tem, fazendo dele o nosso pequeno Balzac" (CANDIDO 2009, p. 546).
} 


\begin{abstract}
A sua arte literária é, portanto, mais consciente e bem armada do que suporíamos à primeira vista. Parecendo um escritor de conjuntos, de largos traços atirados com certa desordem, a leitura mais discriminada de sua obra revela, pelo contrário, que a desenvoltura aparente recobre um trabalho esclarecido dos detalhes, e sua inspiração, longe de confirmarse soberana, é contrabalançada por boa reflexão crítica. Tanto assim, poderíamos dizer, que na verdade não escreveu mais do que dois ou três romances, ou melhor, nada mais fez, nos vinte e um publicados, do que retomar alguns temas básicos, que experimentou e enriqueceu, com admirável consciência estética, a partir do compromisso com a fama, assumido n'O guarani (CANDIDO 2009, p. 548).
\end{abstract}

A consciência demonstrada no trato de temas que Ihe são recorrentes, o cuidadoso realce de detalhes que não apagam a visão de conjunto, assim como uma inspiração moldada pela reflexão criativa laboriosa, são os predicados que permitem um juízo estético positivo da obra de José de Alencar. Empenhado em lastrear uma tradição que se forma vagarosamente e, portanto, utilizando certa régua de cunho evolutivo, Candido reconhece nos romances de Alencar "um refinamento que pressagia Machado de Assis" (CANDIDO 2009, p. 545). Ampliando o uso das categorias schillerianas para a compreensão da formação de uma tradição literária brasileira, pode-se concluir que, como a perda da ingenuidade não é trabalho isolado de indivíduo, mas sim uma obra coletiva como já fora intuído por Machado -, ele com frequência antevê autores e obras em seus antecessores, em uma espécie de gradativa e constante produção de presença, fazendo com que o sentido de sua narrativa seja reconhecido em futuros enunciados por passados incompletos.

Insistir na questão do ingênuo e do sentimental como chave de leitura para a síntese da historiografia literária de Candido demanda certo cuidado para que não seja imposta uma simples antinomia ao ensaio schilleriano. De acordo com Schiller, o poeta "ou é natureza ou a buscará. No primeiro caso, constituise o poeta ingênuo; no segundo, o poeta sentimental" (SCHILLER 1991, p. 60). Numa comparação pautada pelo que caracteriza o poeta ingênuo e o sentimental, ou uma sensibilidade antiga e moderna, respectivamente, Schiller aponta que "fica patente que a meta pela qual o homem se empenha mediante a cultura é infinitamente preferível àquela que alcança mediante a natureza" (SCHILLER 1991, p. 62). Tendo em vista tal assertiva, torna-se patente que Schiller, ao considerar uma sensibilidade moderna, aponta para a natureza como uma espécie de aporia, como retorno almejado pelo espírito cultivado. Não se trataria, no caso do poeta ingênuo, somente de uma representação precisa e calcada na sobriedade, mas do ilusório retorno do homem ao natural. Vejamos as suas palavras sobre a tensão entre natureza e artifício:

Enquanto ainda é natureza pura, quer dizer, não é natureza rude, o homem atua como indivisa unidade sensível e como todo harmonizante. Sentidos e razão, faculdade receptiva e espontânea ainda não se cindiram e muito menos estão em desacordo. Suas sensações não são o jogo informe do acaso, nem seus pensamentos o jogo sem conteúdo da faculdade de representação; aquelas provêm da lei da necessidade; estes, da realidade. Se o homem entrou no estado de cultura e a arte nele pousou a mão, 
suprime-se a harmonia sensível, e ele ainda pode se manifestar apenas como unidade moral, ou seja, empenhando-se pela unidade. A harmonia entre seu sentir e pensar, que no primeiro estado ocorria realmente, agora existe apenas idealmente; já não está nele, mas fora, como um pensamento que deve primeiramente ser realizado, não mais como um fato de sua vida (SCHILLER 1991, p. 60-61, grifos do original).

O que se evidencia no artifício poético moderno é a possibilidade da natureza enquanto representação. $O$ indivíduo moderno apartado da natureza, fragmentado pela impossibilidade de reabilitar sua sensibilidade ingênua, busca reproduzi-la de maneira ideal, como produto do intelecto. Assim, "a natureza o faz uno consigo; a arte o cinde e desune; pelo Ideal, ele retorna à unidade". No entanto, essa busca nunca é satisfeita, permanece sempre em suspenso, pois o Ideal mostra-se inalcançável: "o homem cultivado jamais pode se tornar perfeito em sua espécie, tal como o homem natural pode se tornar na sua". Isso não quer dizer que exista algum tipo de hierarquia entre as duas formas de sensibilidade mencionadas, visto que, "como a meta suprema da humanidade não é alcançável senão por progressão, e como aquele não pode progredir senão à medida que se cultiva", assim, mesmo que se apresente como inatingível, descortina-se enquanto meta traçada por uma educação estética (SCHILLER 1991, p. 61-62).

Em outras palavras, tomadas do ensaio $O$ romancista ingênuo $e$ sentimental, de Orhan Pamuk, enquanto os "ingênuos estão irmanados com a natureza; na verdade, são como a natureza - calma, cruel e sábia", eles gozam de uma espontaneidade que transforma a poesia numa "impressão que a natureza produz neles organicamente e que nunca mais os deixa"; o sentimental, por seu caráter reflexivo, "está extremamente consciente do poema que escreve, dos métodos e técnicas que utiliza e do artifício envolvido no seu empreendimento". Dessa forma, conclui que "o poeta ingênuo não vê muita diferença entre sua percepção do mundo e o mundo em si. Já o poeta moderno, sentimental-reflexivo, questiona tudo que percebe, até mesmo os próprios sentidos" (PAMUK 2011, p. 17-18).

Avançando sobre a passagem da sensibilidade ingênua para a sentimental, talvez seja produtivo recorrer a outro leitor de Schiller, que, por sua vez, exerceu reconhecida influência nas reflexões estéticas de Candido: Georg Lukács. Ao discutir o condicionamento histórico-filosófico do romance, Lukács reverbera o pensamento schilleriano ao qualificar a ingenuidade do escritor:

A ingenuidade do escritor - uma expressão positiva somente para os mais intrinsecamente inartísticos da pura reflexão - é aqui violada, invertida no contrário; e o contrapeso desesperadamente conquistado, o equilíbrio oscilante de reflexões que se suprimem umas às outras, a segunda ingenuidade, a objetividade do romancista, é para tanto um simples sucedâneo formal: ele torna possível a configuração e arremata a forma, mas a própria maneira do remate indica com um gesto eloquente o sacrifício que se teve de fazer, o paraíso eternamente perdido que foi buscado mas não encontrado, cuja busca infrutífera e desistência resignada dão fecho ao círculo da forma (LUKÁCS 2009, p. 86). 
Uma segunda ingenuidade torna-se símbolo não da ausência, mas da presença da técnica. Torna-se expressão da objetividade do escritor, que, ciente de suas possibilidades criativas, a reproduz como sucedâneo da forma, porém, não sem reproduzir, uma vez mais, a perda da naturalidade - artifício da forma que indica complexa trajetória criativa, pois refaz a ingenuidade como sensação advinda de um arranjo orientado por uma imaginação criadora. ${ }^{7}$ Tentando desfazer a antinomia armada no início de seu ensaio, Schiller busca uma espécie de síntese:

Por isso, se às vezes se sente a falta do espírito nas criações do gênio ingênuo, também amiúde em vão se pergunta pelo objeto nos frutos do gênio sentimental. Ambos, pois, embora de modo inteiramente opostos, cairão no vazio; porque ambos, um objeto sem espírito e um jogo do espírito sem objeto, nada são no juízo estético (SCHILLER 1991, p. 95).

A temporalidade evocada como condição indispensável para se pensar as condições de possibilidade da criação literária nos remete, novamente, ao contexto da formação nacional. A importância atribuída por Antonio Candido ao salto dado por Machado de Assis como criador e crítico indica uma espécie de solução provisória para certo devir da literatura nacional; além disso, aponta para a questão fulcral referente ao uso do pecúlio literário - pecúlio compreendido enquanto metáfora que expressa certa resistência do passado à condição moderna e a possibilidade de reordenamento do passado por meio desta mesma condição. ${ }^{8}$ O jogo entre passados e futuros possíveis, expresso na incompletude deliberada do quadro de formação nacional, pressupõe a fundação de uma tradição que permitisse avanços literários na periferia do capitalismo. 0 diálogo criativo com antecessores e contemporâneos demonstra a consciência do legado; em última instância, permite atingir certa maioridade literária. Vejamos as palavras de Antonio Candido:

Se voltarmos porém as vistas para Machado de Assis, veremos que esse mestre admirável embebeu meticulosamente da obra dos predecessores. A sua linha evolutiva mostra o escritor altamente consciente, que compreendeu o que havia de certo, de definitivo, na orientação de Macedo para a descrição de costumes, no realismo sadio e colorido de Manuel Antônio, na vocação analítica de José de Alencar. Ele pressupõe a existência dos predecessores, e esta é uma das razões da sua grandeza: numa literatura em que, a cada geração, os melhores recomeçam da capo e só os medíocres continuam o passado, ele aplicou o seu gênio em assimilar, aprofundar, fecundar o legado positivo das experiências anteriores. Este é o segredo da sua independência em relação aos contemporâneos europeus, do seu alheamento às modas literárias de Portugal e França. Esta, a razão de não terem muitos críticos sabido onde classificá-lo (CANDIDO 2009, p. 436-37).

\footnotetext{
7 Sobre o papel precursor da reflexão crítica que anuncia o destino da forma, ver Lukács (2015).

8 Para a compreensão da metáfora do pecúlio no interior da reflexão crítica de Machado de Assis, sobretudo no que ela implica de deslocamento da oposição entre antigos e modernos, ver Baptista (2003). Sobre a relação entre instinto de nacionalidade e instinto de modernidade, ver Silva (2012).
} 


\section{Considerações finais}

O caráter reflexivo-sentimental da crítica machadiana sintetiza o processo de amadurecimento descrito ao longo da Formação da literatura brasileira: uma ingenuidade clássica que gradativamente dá lugar a um sentimento romântico. Além disso, aponta para um movimento retrospectivo de positivação e qualificação do passado enquanto tradição, enquanto pecúlio necessário para a construção e orientação de um futuro garantidor da autonomia e modernidade literária nacional. A inflexão provocada pelo caráter reflexivo da crítica de Machado potencializa o próprio projeto crítico-formativo de Candido, pois a regularidade e a sedimentação reflexiva não somente sublinham a dimensão do artifício que envolve a representação da realidade, mas também vislumbram o discernimento poético necessário para transformar a experiência particular em matéria literária com pretensões universais.

Essa sensibilidade cultivada ou intermediada parece ser o ponto de chegada da narrativa de Candido. O equilíbrio entre interioridade e o dado externo, a maturidade para recriar o natural tolhendo os jorros emotivos, uma disposição mental para o reconhecimento da técnica, definem a longa atividade formativa das letras nacionais. Em suma, ao se destacar a centralidade da consciência crítica para a maturidade nacional, o esquema narrativo de Formação pretende sublinhar o valor de certa manifestação do passado. A sua historiografia literária, voluntariosa diante da percepção da vontade de expressão de uma identidade brasileira, busca erigir um patrimônio comum, um passado que se manifesta no presente como monumento coletivamente lapidado, pecúlio disponível às gerações futuras, indicando com isso as permanências advindas das influências. A linearidade figura como cabedal acessível, podendo tornar-se uma masmorra para os escritores considerados menores, pelo insucesso de suas criações que somente corroboram a sedimentação, ou uma escada ou laboratório para aqueles que se utilizam dela de forma criativa - lembremos a imagem da corrida de bastão, utilizada por Candido para sintetizar sua ideia de tradição.

A questão aqui é a peculiaridade da historiografia literária proposta por Candido, uma historiografia sentimental que parte do desejo de se ter uma literatura e termina com a presença de uma percepção sentimental do passado. A passagem da ingenuidade árcade ao sentimentalismo da crítica romântica permite a descrição de uma totalidade, sem completude, para valermo-nos das palavras de Waizbort. Dessa maneira, o desfecho de Antonio Candido representa intercessão entre a expressão do sentimento íntimo machadiano, uma crítica ao nacionalismo de superfície e de traço amaneirado dos escritores empenhados na divulgação das cores locais, e a atitude reflexivo-sentimental, que pressupunha uma interiorização dos elementos externos. O recorte transitório que descreve a maturidade literária nacional depende do movimento reflexivo e crítico que torna universal a experiência estética, esboçando uma espécie de segunda natureza que substituiria a natureza perdida. 


\section{Referências bibliográficas}

ARANTES, Paulo Eduardo. Providências de um crítico literário na periferia do capitalismo. In: ARANTES, Otília Beatriz Fiori. Sentido da formação: três estudos sobre Antonio Candido, Gilda de Mello e Souza e Lúcio Costa. Rio de Janeiro: Paz e Terra, 1997, p. 11-66.

ARAÚjO, Ricardo Benzaquen de. Através do espelho: subjetividade em Minha formação de Joaquim Nabuco. Revista Brasileira de Ciências Sociais, v. 19 , n. 56 , p. 5-13, 2004.

ARAUJO, Valdei Lopes de. Política como história, como literatura: um Estadista do Império. In: ROCHA, João César de Castro; ARAUJO, Valdei Lopes de (Org.). Nenhum Brasil existe. Rio de Janeiro: Topbooks, 2001, p. 303-312.

ASSIS, Machado de. Instinto de nacionalidade: notícia da atual Literatura Brasileira. In: COUTINHO, Afrânio dos Santos. Caminhos do pensamento crítico. Rio de Janeiro: Ed. Americana; Prolivro, 1974, p. 343-351. v. I.

BAPTISTA, Abel Barros. A formação do nome - Duas interrogações sobre Machado de Assis. Campinas: Ed. Unicamp, 2003.

O cânone como formação: a teoria da literatura brasileira de Antonio Candido. In: __ O livro agreste: ensaio de curso de literatura brasileira. Campinas: Ed. Unicamp, 2005.

CANDIDO, Antonio. Formação da literatura brasileira: momentos decisivos, 1750-1880. Rio de Janeiro: Ouro sobre Azul, 2009.

GOMES JÚNIOR, Guilherme Simões. Palavra peregrina: $O$ Barroco e o pensamento sobre as artes e letras no Brasil. São Paulo: Edusp, 1998.

LIMA, Luiz Costa. Limites da voz: Montaigne, Schlegel. Rio de Janeiro: Rocco, 1993.

. Concepção de história literária na Formação. In: D'INCAO, Maria Angela; SCARABÔTOLO, Eloísa Faria (Org.). Dentro do texto, dentro da vida: ensaios sobre Antonio Candido. São Paulo: Companhia das Letras: Instituto Moreira Salles, 1992, p.153-169.

LUKÁCS, Georg. A teoria do romance: um ensaio histórico-filosófico sobre as formas de grande épica. São Paulo: Duas Cidades; Editora 34, 2009.

. Sobre a forma e a essência do ensaio: Carta a Leo Popper. In:

A alma e as formas. Belo Horizonte: Autêntica, 2015, p. 31-53.

OSBORNE, Peter. Modernity is a qualitative, not a chronological, category. New Left Review, n. 192, p. 65-84, 1992.

PAMUK, Orhan. O romancista ingênuo e sentimental. São Paulo: Companhia das Letras, 2011.

ROCHA, João Cezar de Castro. Machado de Assis: por uma poética da emulação. Rio de Janeiro: Civilização Brasileira, 2013. 
RODRIGUES, Henrique Estrada. O conceito de formação na historiografia brasileira. In: MEDEIROS, Bruno Franco; DE SOUZA; Francisco Gouvea; BELCHIOR, Luna Halabi; RANGEL, Marcelo de Mello; PEREIRA, Mateus H. F. (Org.). Teoria e historiografia: debates contemporâneos. Jundiaí: Paco, 2015, p. 253-275.

SCHILLER, Friedrich. A educação estética do homem. São Paulo: Iluminuras, 2002.

Poesia ingênua e sentimental. São Paulo: Iluminuras, 1991.

WAIZBORT, Leopoldo. A passagem do três ao um: crítica literária, sociologia, filologia. São Paulo: Cosac Naify, 2007.

SILVA, Daniel Pinha. Apropriação e recusa: Machado de Assis e o debate sobre a modernidade brasileira na década de 1870. Tese (Doutorado em História) - Pontifícia Universidade Católica do Rio de Janeiro, Rio de Janeiro, 2012.

SUZUKI, Márcio. Apresentação. In: SCHILLER, Friedrich. Poesia ingênua e sentimental. São Paulo: Iluminuras, 1991, p. 9-40. 